\title{
LA «RECONSTRUCCIÓN» DEL TEATRO ROMANO DE SAGUNTO. REFLEXIONES EN TORNO A UNA POLÉMICA*
}

POR

\author{
ANTONIO ALMAGRO \\ Escuela de Estudios Arabes \\ C.S.I.C. Giranada
}

\begin{abstract}
RESUMEN
Se analizan en este articulo algunos aspectos referentes a la controvertida obra realizada por los arquitectos G. Grassi y M. Portaceli en el teatro romano de Sagunto, y en especial ideas como la supuesta recuperación del espacio original o el pretendido respeto a las estructuras originales. Se hacen igualmente algunas reflexiones sobre la aún más polémica sentencia dictada por el Tribunal Superior de Justicia del Pais Valenciano que ha declarado ilegales dichas obras.
\end{abstract}

\section{SUMMARY}

The paper analyses some aspects of the very controverted restoration carried out on the Roman theatre of Sagunto by G. Grassi and M. Portaceli, and specially the ideas of the recovering of the original space and the care of its structures. Some meditations about the judgement from the Tribunal Superior de Justicia del Pais Valenciano that has declared illegal the works, are also presented.

La conservación del Patrimonio Histórico no suele ser compatible, en general con actuaciones grandilocuentes. Una labor eficaz de protección y tutela de nuestros monumentos nunca tendrá un impacto sobre la opinión pública similar al que pueda tener la inauguración de una presa o la apertura de una nueva carretera. Pienso que un objetivo perfectamente asumible como óptimo en un programa politico podria ser transmitir ese patrimonio al menos en el mismo estado que como se recibió. Digo en el mismo estado físico, no en la misma

- El comité de redacción de AEspA ha decidido la edición de este texto atendiendo a su interés, a pesar de que se ha publicado previamente otro similar del mismo autor. situación de deterioro progresivo, esto es, cada vez más deteriorado, que es a lo que estamos acostumbrados. Naturalmente, un logro como éste, muy difícil de alcanzar si lo aplicamos a la totalidad o al menos a la generalidad de nuestro patrimonio, es dificilmente vendible dentro de una cultura política más basada en los grandes gestos que en acciones auténticamente eficaces de una politica programada y a largo plazo. Esta actitud no es exclusiva de ningún grupo politico y de esta responsabilidad no está tampoco exenta la misma sociedad.

Además, la conservación del patrimonio no se presta al desarrollo de acciones eminentemente creativas, sin que por ello deban descartarse. Pero parece evidente que, en la acción conservadora, deben primar los valores del bien a conservar sobre los que nuestra creatividad actual pueda aportar. Resultan por ello extrañas y difícilmente defendibles actitudes, y más aún acciones, que justifican a ultranza la aportación de creaciones arquitectónicas actuales sobre nuestros monumentos, amparadas dentro de lo que debieran ser acciones de conservación, máxime cuando se financian con fondos destinados a este último fin.

Cuando grandes gestos políticos en materia de cultura junto con anhelos de creatividad a ultranza toman como excusa un monumento histórico, no es dificil que surja un problema como el del teatro romano de Sagunto (figs. 1 y 2 ).

La propuesta de G. Grassi y M. Portaceli parte de unos criterios que aparentemente pueden tomarse como muy defendibles, pero que analizados en detalle no soportan una critica 

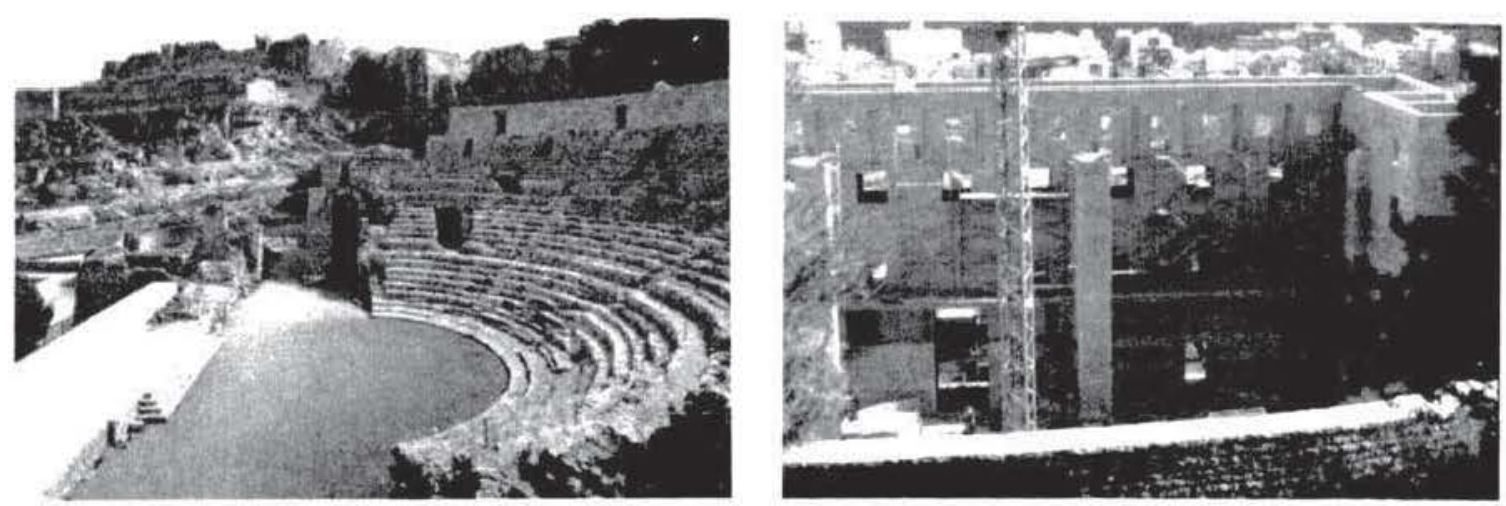

Figura 1 y 2. Aspecto del teatro romano de Sagunto antes de la interiencion y durante el desarrollo de la obra

rigurosa. G. Grassi atribuye a anteriores intervenciones objetivos y criterios que, cuando menos, hay que refutar de infundados y subjetivos, máxime si no se tuvo ocasión de conocer y tratar a quienes llevaron a cabo tales intervenciones '. En base a ello, se establecen justificaciones de la actuación, pero que lejos de abordar e intentar corregir pasados defectos y errores, acaba asumiéndolos o incluso consagrándolos, al no hacer distinción entre lo realmente auténtico y lo añadido en este siglo. Merece hacerse especial hincapié en este tema, pues parece haber sido uno de los argumentos más utilizados por quienes posteriormente han defendido a ultranza la obra de Grassi y Portaceli, al considerar los restos del teatro una ruina artificial y no original. Evidentemente ha habido errores en anteriores restauraciones, tanto de criterio como de método, y algunos de ellos ya fueron cientificamente criticados en 1979 , cuando publiqué la primera planimetria fotogramétrica del teatro y una explicación de las obras por mi realizadas en 1977 y $1979^{2}$. Entonces propuse que no se debia intervenir de

\footnotetext{
Quisiera aclarar que en ninguin momento me he podido sentir aludido por tales criticas, pues mi limitada intervención en el teatro no supuso ninguna reconstrucción sino sólo la consolidación de piedras movidas de la zona de la cavea y la colocación de rejas y barandillas de seguridad.

ALMAGRO, A., Estudio fotogramétrico del teatro romano de Sagunto, Saguntum, 14. 1979. pàg. 176. Debo resaltar la existencia de una errata en la linea 15 de esa página donde aparece "las paredes" en lugar de "los parodoss.
}

nuevo en el monumento, que por otro lado no presentaba ya problemas graves de conservacion. hasta que no se realizara una seria y exhaustiva investigación previa del mismo. Esta investigación ha sido realizada en fecha reciente al margen de la obra, $y$ sin que haya tenido influencia directa en ella ${ }^{3}$. Incluso, al contrario, los últimos desescombros y limpiezas de estructuras antiguas se han realizado con las obras ya muy avanzadas y sin que pudieran influir en modificaciones sobre una estructura rigidamente proyectada. En suma, no puede afirmarse que el proyecto se haya basado en un conocimiento científico ni riguroso del edificio, ni menos aún, que haya sido exquisitamente respetuoso con éste. Ni se hizo la adecuada investigación previa a la fase de proyecto, ni los resultados obtenidos de los hallazgos o estudios posteriores han provocado las modificaciones que hubiera sido de rigor, lo que es dificilmente compatible con la afirmación de delicadeza y respeto al monumento.

Como testimonios en este sentido, cabe señalar que aún recuerdo haber visto, en una visita realizada en los primeros momentos de la obra, estructuras originales romanas de opus vittatum (sillarejos) cortadas con disco de carborundo para abrir cajas en que insertar muros de nueva construcción, inexistentes en la obra original. Otro ejemplo: el muro de cierre del

LARA, S. El teatro romano de Sagunto. Ginesis e hipótesis de reconstruccion. Valencia, 1992. 
postscaenium, seguramente ejecutado en dos fases en época romana, presentaba exteriormente una clarisima estructura de machones de refuerzo de opus quadratum, cuyos grandes sillares habian sido arrancados ya de antiguo, pero de los que quedaban las huellas, con relleno de opus vittatum. De tal estructura no ha quedado hoy visible ni legible absolutamente nada, al haberse construido sobre sus restos un muro nuevo en su casi totalidad, además en sillarejo similar al opus vittatum, lo que contribuye aún más a aumentar la confusión actual y futura.

Respecto a la pregonada calidad de la obra y del diseño, invitaría a quien visite la obra a que, haciendo un ejercicio de imaginación, traslade el graderio reconstruido a un lugar cualquiera, fuera de las ruinas del teatro. La tosquedad del diseño, barandilla incluida, dudo que contenga méritos para salir publicado en ninguna revista de arquitectura. Eso sin entrar a juzgar la arbitraria decisión de interrumpir las scalue en los balteus, contra las claras evidencias que la ruina aportaba. Por otro lado, la forma constructiva adoptada resulta igualmente torpe. Un aplacado de piedra blanca («travertino" de Teruel), con color disonante sobre la masa gris de la piedra local, con la que sin duda estuvo construido el graderio, se ha asentado sobre un relleno de piedra menuda y mortero de cemento. Este relleno es semejante al primitivo romano, aunque evidentemente alcanza cotas superiores, pues éste servía para asiento de grandes sillares, con igual altura que las gradas. Es decir, se ha utilizado la misma técnica antigua de asiento de piedras (al menos aparentemente), pero alcanzando volumen y niveles que nunca tuvo la fábrica primitiva. La colocación de una red de material plástico como elemento separador de lo nuevo y lo viejo, ni resulta estéticamente válida ni mucho menos efectiva para permitir una supuesta reversibilidad de la intervención, pues no ha evitado en absoluto la adherencia de ambas fábricas.

Otro detalle que no sabría si atribuir a mal diseño o a simple ignorancia, pero en todo caso sí a falta de sensibilidad estética, lo constituye el remontaje o supuesta anastylosis de algunos elementos de los órdenes que decoraron el frons scaena. Realmente, tal montaje más parece ser una caricatura que un intento serio de mostrar o de hacer intuir al visitante lo que pudo ser la ornamentación del teatro. Las columnas se han dispuesto con una proporción absolutamente rechoncha, lo que las priva de la elegancia $y$, en especial, de la armonia y belleza de proporciones que caracteriza los órdenes clásicos. Parece que se ha supuesto que la escena tuvo triple orden, lo que no se sustenta en ninguna evidencia y que sólo el montaje realizado se encarga de contradecir con absoluta claridad.

En cuanto a la reconstrucción del edificio escénico debemos decir que nos parece, antes que nada, bastante confusa en su apariencia final, aparte de errónea en la altura total, pues queda achaparrado al no haber alcanzado la altura que debió tener originalmente, sin que con ello queramos dar justificación a la idea de reconstruir la escena. Una organización de los muros que recuerda las formas de las valvae pero que apenas levantan unos pocos metros, creo que lejos de ayudar a intuir la forma original de la escena induce a confusión.

El actual espectador o visitante que entre en el espacio del teatro encontrará que, de las superficies que se le presentan ante la vista, ni siquiera una cuarta parte son restos originales romanos, pues las zonas que ahora no han sido afectadas por las nuevas fábricas son precisamente las que sufrieron más fuertes intervenciones en pasadas obras de restauración. En resumen, pienso que las ruinas del teatro romano de Sagunto sólo han servido, en este caso, de excusa para realizar una construcción que, de haber sido hecha en otro lugar, difícilmente habria merecido justificación y menos aún el aplauso de algunos sectores casi exclusivamente circunscritos al campo del diseño arquitectónico actual.

Y entramos aquí en el tema más difícil y polémico de toda la intervención. ¿Hasta qué punto se justifica una intervención actual de esta envergadura en un monumento histórico? Se han argumentado dos tipos de justificaciones que merecen un tratamiento diferencial. En primer lugar se arguye con notable insistencia, sobre todo en los últimos años, que históricamente siempre ha habido intervenciones de cada época en los edificios, llegando algunas a te- 
ner tanta o mayor calidad que la obra original. Es una evidencia histórica que no pretendo refutar pero que debe ser entendida y analizada en el marco de cada época. Si algo caracteriza nuestro tiempo es la indudable existencia, no sólo de forma elitista sino sentida por la mayoria de la sociedad, de una mayor conciencia histórica y de un respeto hacia el legado del pasado, en este caso arquitectónico, que es expresión y sintesis de la misma Historia. No en vano nuestra época se caracteriza por haber plasmado este sentir, entre otras cosas, en legislaciones protectoras de este legado.

Intervenciones como la construcción del palacio de Carlos V en la Alhambra proyectada por Pedro Machuca, o del crucero de la catedral en la mezquita de Córdoba por Hernán Ruiz, son obras que sólo se comprenden y se justifican en su época y en las circunstancias en las que se hicieron. Son obras geniales, pero que desde nuestra conciencia histórica sería injustificable y anacrónico que hoy se plantearan y menos que se realizaran. Porque en este caso no se trata de opiniones sobre gustos, sino de la esencia misma del concepto de conservación de un patrimonio que la sociedad considera propio, universal y necesitado de ser legado integramente a las generaciones futuras. Y no debemos olvidar, por otro lado, que esas transformaciones históricas de nuestros monumentos más preciados fueron el fruto de voluntades que hoy consideramos autoritarias, algunas ejecutadas, como la de la mezquita de Córdoba, contra el mayoritario sentir popular en una época en que, evidentemente, éste no contaba en las tomas de decisiones. Argumentar que igual que se hizo en esas épocas se puede hacer hoy, es un contrasentido histórico, $y$, en todo caso, y pese a toda la modernidad que se quiera imprimir a la obra, será en su concepción y actitud, arquitectura de otra época, no arquitectura actual.

Con todo esto, no pretendo argumentar que no se pueda aportar arquitectura actual a nuestros monumentos. En alguna ocasión puede resultar incluso imprescindible, porque si existe absoluta necesidad de construir algo nuevo, esto debe llevar la impronta de nuestro tiempo. Pero en cualquier caso debe respetar la esencia y la naturaleza del monumento, no sobreponerse a él, ni apabullarlo, ni menos ocultarlo o enmascararlo detrás de la obra actual. Y respetar su esencia puede en muchos casos querer decir respetar su estado de ruina que es también y ante todo, la expresión de su historia, especialmente cuando no existe una necesidad imperiosa por razones de conservación o de uso.

Conviene aqui preguntarse hasta qué punto es necesario que todos los monumentos vuelvan a recuperar un uso, fuera del que evidentemente ya tienen de ser expresión del pasado y servir de lección histórica y estética para hoy $y$ el futuro. En una palabra, en ningún modo se justifica siempre el utilitarismo a ultranza de los monumentos. Hay muchos que merecen quedar como meros simbolos. Y si hace falta un teatro, y se quiere que tenga la forma de un teatro romano, evidentemente hay muchos lugares en que poder edificarlo.

Otro de los argumentos utilizados en defensa de esta obra es la supuesta restauración del espacio original. Mi buen amigo Antoni González, Cap del Servei de Patrimoni Arquitectonic de la Diputació de Barcelona, interpreta la idea plasmada en la Carta de Venecia de exigir el respeto a la autenticidad, considerando legitimo recuperar el espacio original como único realmente auténtico, no restringiendo el concepto de autenticidad a la sola materialidad.

$\mathrm{He}$ de reconocer que la idea siempre me ha parecido sugestiva y fundamentada, aunque como todo en esta vida, debe asumirse con matices y no de forma absoluta. La recuperación del espacio primigenio original, considerado como el único de verdad auténtico, choca evidentemente en la mayor parte de los casos con la conservación de la materia auténtica del monumento, que tiene que enmascararse y aun a veces desaparecer. Eso sin contar con que habria que considerar igualmente "original» el espacio resultante de las distintas aportaciones históricas. Lo que no tiene sentido es que una restauración cree un espacio nuevo o transforme el original, sobre todo por la vía de la transformación del color, la textura o los propios materiales. Y por otro lado, en un monumento llegado a nosotros en estado de ruina, su espacio ruinoso no será el supuestamente «auténti- 
co" original, pero puede llegar a cobrar significación propia como ruina, y por tanto nueva autenticidad, según el valor que la sociedad y la cultura le den. Las ruinas del Partenón no reflejan el espacio original, pero contienen hoy y para nuestra sociedad valores espaciales, como tales restos. Incluso hay quien llega a contradecir la validez de la anastylosis de determinados monumentos, cuyos restos caidos expresan muchas veces con absoluta claridad realidades $\mathrm{y}$ hechos históricos o acciones de la naturaleza. El atractivo y la veneración que para nuestra sociedad encierran muchos de nuestros monumentos, incluso desde el punto de vista de la atracción turistica, no cabe duda que en muchos casos se desvanecerian tras actuaciones de reconstrucción, aunque fuera por la mera vía de la recuperación del espacio original «auténtico». $Y$ en esto creo que no sólo hay que ver una mera atracción romántica hacia la ruina, sino el reconocimiento de los valores simbóli$\cos$ y testimoniales que generalmente los monumentos, como realidad y documento histórico, tienen para la sociedad.

En suma, la idea de recuperar el espacio original como único auténtico no puede tomarse como válida en todos los casos y, desde luego, cuando hay serias dificultades para conocer su auténtica forma y vibración, y más cuando exige realizar un volumen de obra que rivaliza con las partes originales conservadas, resulta más que dudosa su validez como criterio de actuación.

$\mathrm{Y}$ para colofón, y como los males nunca vienen solos, a todos los problemas antes tratados ha venido a juntarse una sentencia judicial, que de llegar a ser firme y crear jurisprudencia puede constituir un precedente de consecuencias dificilmente predecibles. La sentencia del Tribunal Superior de Justicia del País Valenciano declarando ilegales las obras que acabamos de analizar, creo que merece también una detenida reflexión. La ley del Patrimonio Histórico Español, en que se ha basado la sentencia, es una ley de aplicación eminentemente administrativa, que tiene su desarrollo principalmente a través de criterios técnicos. Pero no puede evitarse que la acción popular prevista en la ley haya planteado una demanda ante los tribunales, ya que la administración. promotora de la obra y a su vez responsable de la tutela del monumento, se mostró insensible a las protestas contra la intervención. $\mathrm{Y}$ a este respecto tengo que decir que me resulta dificilmente imaginable que una obra de este carácter y planteamiento hubiera contado con la aprobación administrativa si llega a ser promovida desde una iniciativa privada.

La sentencia que ha declarado ilegal la obra se ha basado en el articulo 39.2 de la ley del Patrimonio Histórico Español, que en realidad contiene una nueva redacción, algo más matizada, del artículo 19 de la antigua ley del Tesoro Artístico que prohibia taxativamente toda reconstrucción en los monumentos, tratando de erradicar los criterios en que se basaron muchas de las restauraciones del siglo pasado y de comienzos de éste. El problema es que, mientras el reglamento de la antigua ley remitía la interpretación de los criterios a aplicar a una junta de técnicos y expertos que, junto con el arquitecto responsable de las obras, debia decidir cómo actuar en cada caso, la nueva ley deja prácticamente la determinación de los criterios en manos de los responsables politicos, que son los únicos con capacidad de decisión. Es decir, las decisiones son unipersonales, pese a que puedan existir asesoramientos. Junto a esto, la ley actual ha pretendido matizar la dureza de la redacción de la antigua ley, pero incluyendo términos que, cuando menos, siguen teniendo un significado un tanto ambiguo, con determinadas connotaciones semánticas que obedecen más a interpretaciones de las mentes de algunas personas que al significado que generalmente se les da. Por ello, no es de extrañar que los jueces hayan dado una interpretación estricta y literal, ante la falta de una correcta definición por parte del texto legal, de lo que se ha querido entender con cada término. $Y$ de todos modos, creo que el problema tampoco se resolverá con pretendidas nuevas redacciones de la ley, pues cuanto más intentemos definir y precisar, por la vía de la reglamentación, los criterios de lo que debe ser una correcta restauración, más dificultades crearemos. Creo que es imposible pretender que la ley garantice una correcta restauración de los monumentos. Ésta debe ser fruto, ante todo, del sentido común y 
de un cierto consenso en la defínición de lo licito y lo correcto, fruto de los deseos generalmente sentidos por la sociedad y de una sosegada discusión entre aquellos sectores implicados y realmente interesados en la protección del Patrimonio Cultural. Porque al fin y al cabo, los criterios de restauración serán siempre expresión de una situación cultural concreta $y$, probablemente, siempre cambiantes. Pero en todo caso, no deberían responder nunca a decisiones políticas y menos unipersonales.

Es comprensible que una parte de la sociedad haya entendido que la obra ha supuesto una agresión contra el monumento. $\mathrm{Y}$ también es comprensible que hayan intentado detener esa agresión por todos los medios, incluidos los legales. Quizás el legislador no se referia precisamente a este tipo de obras cuando redactó la ley, pero tampoco puede decirse que la sentencia carezca de fundamento. Creo que lo ideal hubiera sido que el tema no se hubiera planteado nunca ante los tribunales, sencillamente porque no se hubieran realizado las obras en cuestión, que por otro lado ni eran tan necesarias ni mucho menos imprescindibles, máxime si consideramos el estado general en que se encuentra el resto de nuestro Patrimonio y la necesidad de rentabilizar y optimizar la aplicación de los escasos recursos que a él se destinan

\section{ADDENDUM}

A

«GIJÓN EN EL PERÍODO TARDOANTIGUO». AEspA 65, 1992* POR

\section{CARMEN FERNÁNDEZ OCHOA, PALOMA GARCÍA DÍAZ Y ALEXANDRA USCATESCU BARRÓN \\ Universidad Autónoma de Madrid}

Gerona
1. Camós.
2. Rosas.
3. L'Escala.
4. Sant Marti d'Empúries.
5. Vilademat.
6. Torroella de Montgri.
7. Sarria de Ter.
8. Gerona.
9. Castell d'Aro.
10. Sant Feliu de Guixols.

\section{Barcelona}

11. Sant Pol del Mar.

12. Mataró.

13. Alella.

14. Teiá.

15. Vilassar.

16. Tiana.

17. El Masnou.

18. Badalona.

19. Barcelona.

20. Palau de Plegamans.
21. Sentmenat

22. Tarrasa

23. Rubi.

24. Sant Cugat del Vallés.

25. Viladecans

26. Sant Boi de Llobregat

27. Molins de Rei.

28. Pallejá.

29. Sant Joan Despi.

30. Odena.

31. Sant Pere de Ribes.

32. Vilanova i La Geltrú.

33. Maians.

34. Roca Roja

\section{Tarragona}

35. Tarragona.

36. Constanti.

37. Ascó.

38. Horta de Sant Joan.

Lérida

39. Lérida.

40. Albesa.

\section{Castellón}

41. Cervera del Maestrazgo.

42. Benassal.

43. Castelnovo.

44. Nules.

\section{Valencia}

45. Sagunto.

46. Valencia.

47. Guadasuar.

48. Tous.

49. Cullera

50. Castelló de Rugat.

\section{Alicante}

51. Denia.

52. Jávea.

53. Calpe.

54. Alicante.

55. Santa Pola.

56. Elche.

57. Aspe
Mallorca

58. Alcudia.

59. Porto Cristo.

60. Colonia Sant Jordi.

\section{Menorca}

61. Fornells.

62. Cales Coves (Alayor)

63. Puerto de Mahón.

64. Favaritx.

Ibiza

65. Ibiza

66. Playa d'en Bossa.

67. Can Sorá.

Formentera

68. Espalmador.

Murcia

69. Cieza.

70. Ulea.

- En el anterior volumen de $A E \operatorname{sp} A$ (n. ${ }^{\circ} 65,1992$, págs. 105-149) se omitió, debido a un error de edición, el siguiente listado de topónimos que acompañaba los mapas del artículo. 